\title{
Resistance of Hydrogen Embrittlement on Hot-sheared Surface during Die-quench Process
}

\author{
Takashi MATSUNO, ${ }^{1)^{*}}$ Yoshihito SEKITO, ${ }^{1)}$ Eisaku SAKURADA, ${ }^{11}$ Tamaki SUZUKI,, Kaoru KAWASAKI ${ }^{1)}$ and \\ Masayoshi SUEHIRO ${ }^{2)}$
}

1) Nippon Steel and Sumitomo Metal Corporation, 20-1 Shintomi, Futtsu, 293-8511 Japan.

2) Nippon Steel and Sumikin Technology Corp. Ltd., 20-1 Shintomi, Futtsu, 293-8511 Japan.

(Received on April 21, 2014; accepted on May 22, 2014; originally published in Tetsu-to-Hagané, Vol. 100, 2014, No. 3, pp. 359-364)

\begin{abstract}
This study investigated the resistance of hydrogen embrittlement on a hot-sheared and quenched surface of $22 \mathrm{MnB} 5$ steel sheets. The specimens were sheared at $750^{\circ} \mathrm{C}$ and $650^{\circ} \mathrm{C}$ after austenitization, and then quenched by water cooling. Additionally, these specimens were cathodically hydrogenized for $48 \mathrm{~h}$ to accelerate cracking by hydrogen embrittlement. This sequence resulted in a residual tensile stress of over $1 \mathrm{GPa}$ on the hot-sheared surface and a diffusible hydrogen density of about $1.5 \mathrm{ppm}$. Despite these severe conditions, cracking by hydrogen embrittlement did not arise. The state of the microstructure in the vicinity of the sheared surface might cause this high resistance against cracking. Indeed, sub-micron grained ferrite or deformed uncertain soft and hard phases, which might be more ductile than martensite, were observed around the sheared surface.
\end{abstract}

KEY WORDS: hot stamping; shearing; cutting; quenching; hydrogen embrittlement; boron steel; fine grain.

\section{Introduction}

Hot stamping processes using steel sheets comprise austenitization by heating, press forming, and quenching. In comparison with cold stamping processes using ultra-high strength steel sheets, hot stamping processes have merits of forming force reduction and low spring-back. ${ }^{1,2)}$ From these merits, hot stamping processes are now rapidly prevailing for producing high strength steel parts of automobiles ${ }^{1)}$ owing to the increasing demand for vehicle weight reduction and improvement of crashworthiness qualities.

On the other hand, hot stamping processes have some tasks to improve productivity. For example, hot stamping processes cost high device fees and long tact time. ${ }^{1,2)}$ Developing of the trimming (or piercing) method is one of these tasks. Presently, in many hot stamping processes, quenched parts are trimmed (or pierced) by laser cutting in spite of these high cost and low productivity. That is because tool wear becomes serious in the case when quenched parts are sheared(shear cut). Though shearing (shear cutting) generally presents a lower cost and higher productivity than laser cutting, cost-effectiveness of laser cutting is possibly superior to that of shearing ${ }^{3}$ including tool renewing cost in continuous shearing of quenched parts. In addition to the cost-effectiveness problem, shearing of high strength materials like quenched steels risks hydrogen embrittlement cracking. ${ }^{4-6)}$ Actually, cold-sheared surface of a quenched steel sheet is cracked under the conditions of higher diffus-

* Corresponding author: E-mail: matsuno.8m7.takashi@jp.nssmc.com DOI: http://dx.doi.org/10.2355/isijinternational.54.2369 ible hydrogen density and residual tensile stress than their criteria. $^{7,8)}$

To solve the above tasks, hot-shearing has been developed in recent years. Two types of hot-shearing methods have been considered before now. The first type is shearing after reheating of quenched parts. ${ }^{9,10)}$ The second type is simultaneously shearing during a hot forming process before quenching. ${ }^{71-13)}$ As a merit of applying these two types of hot-shearing methods, tool wear is expected to be improved because shearing force is drastically smaller than that in cold-shearing. ${ }^{9-13)}$ Additionally, the first type of hotshearing suppresses hydrogen embrittlement cracking on hot-sheared surface because of softening and reduction of residual tensile stress by a tempering process. ${ }^{10)}$ Though details of mechanism have not been clarified, the second type of hot-shearing that include no tempering process also presents low residual tensile stress on hot-sheared surface to suppress hydrogen embrittlement cracking. ${ }^{7)}$

This paper provides further analysis of the second type of hot-shearing. The analysis clarified that hydrogen embrittlement cracking on hot-sheared surface is suppressed despite an approximately $1.5 \mathrm{ppm}$ hydrogen density and a $1 \mathrm{GPa}$ residual tensile stress. The paper also discussed mechanism of the suppression of hydrogen embrittlement cracking by microstructural observation and hardness measurement in the vicinity of the hot-sheared surface. These result and discussion contributes further prevailing of hot-shearing because hot stamping processes cannot avoid hydrogen ingress and residual tensile stress induced by rapid heat transferring. 


\section{Experimental Procedure}

\subsection{Material}

Boron steel sheets with aluminide coating and $2.3 \mathrm{~mm}$ thickness were used for this study. The grade of steel sheets is $22 \mathrm{MnB} 5$, where chemical compositions are shown in Table 1. Regarding hardness, the non-deformed material after quenching presents a value of $480 \mathrm{Hv} 0.1$ (4.7 GPa). Moreover, cold-sheared surface of the quenched material was cracked by hydrogen embrittlement as shown in Fig. 1.

$M_{s}$ of the material was identified as $420^{\circ} \mathrm{C}$ by a volume dilatation measurement using a thermo simulator. $A_{\mathrm{r} 3}$ was measured as $580^{\circ} \mathrm{C}$ (the measurement method for $A_{\mathrm{r} 3}$ is described in the following paragraph).

The $A_{\mathrm{r} 3}$ was identified from a cooling history of material temperature. Firstly, the material was austenitized in a furnace for $90 \mathrm{~s}$ at $950^{\circ} \mathrm{C}$. Subsequently, the material was set on four pins attached on a die-face, the same as in a hotshearing experiment explained in section 2.2, and kept for a few minutes. The cooling history measured in this process is shown in Fig. 2. This figure shows that cooling rate becomes almost zero at the $580^{\circ} \mathrm{C}$. Since this zero cooling rates is caused by transformation from austenite to ferrite, ${ }^{14)}$ we identified this temperature as $A_{\mathrm{r} 3}$.

\subsection{Hot-shearing}

Figure 3 shows the tools for the hot-shearing. As shown

Table 1. Chemical compositions of a material (mass $\%$ ).

\begin{tabular}{ccccc}
\hline $\mathrm{C}$ & $\mathrm{Si}$ & $\mathrm{Mn}$ & $\mathrm{B}$ & Others \\
\hline 0.2 & 0.2 & 1.2 & 0.003 & $\mathrm{Ti}, \mathrm{Cr}$ \\
\hline
\end{tabular}

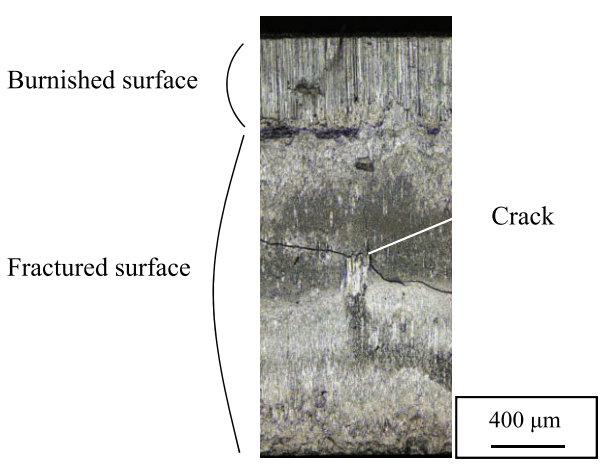

Fig. 1. A crack on the cold-sheared surface of the quenched material. (Online version in color.)

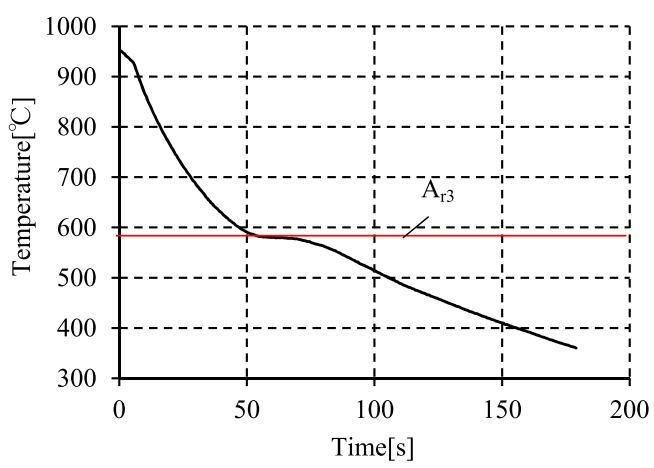

Fig. 2. Cooling history of material temperature. (Online version in color.) in Fig. 3, the hot-shearing cut off a rectangular part with 20 $\mathrm{mm} \times 150 \mathrm{~mm}$ from the longitudinal center of a $200 \mathrm{~mm} \times$ $150 \mathrm{~mm}$ blank sheet. In this regard, clearance between the punch and die is $0.15 \mathrm{~mm}$ (6.5\% of the material thickness). Clearance between the punch and blank holder is almost zero, so that the entire material surface contacts the tools during the hot-shearing.

In this experiment, we controlled temperature at the start of shearing. For easy control of temperature, the blank sheet is set on pins supported by springs. This setting avoids rapid cooling by contact between the blank sheet and tools.

The process of the hot-shearing is as follows: First, a blank sheet was austenitized in a furnace for $90 \mathrm{~s}$ at $950^{\circ} \mathrm{C}$. Second, the blank sheet is moved and kept on the tools until the blank sheet cools to predefined temperatures, $750^{\circ} \mathrm{C}$ and $650^{\circ} \mathrm{C}$ (these temperatures are higher than $A_{\mathrm{r} 3}$ ). The cooling history shown in Fig. 2 identified the time when the blank sheet cools to the predefined temperatures. Afterward, the blank is sheared and quenched subsequently by a water spout from the die surface.

\subsection{Analysis of Sheared Surface}

2.3.1. Estimation of Hydrogen Embrittlement Cracking

Hydrogen embrittlement cracking on sheared surface was estimated by optical observation. As shown in Fig. 4, specimens for this observation were cut from the rectangular parts after hot-shearing.

In addition, the specimens were cathodically hydrogenized to accelerate hydrogen embrittlement cracking. In this hydrogen charge, the specimens were soaked in sodium thiocyanate solution with a platinum electrode. An electric current of $0.1 \mathrm{~mA} / \mathrm{cm}^{2}$ was impressed for $48 \mathrm{~h}$ under the

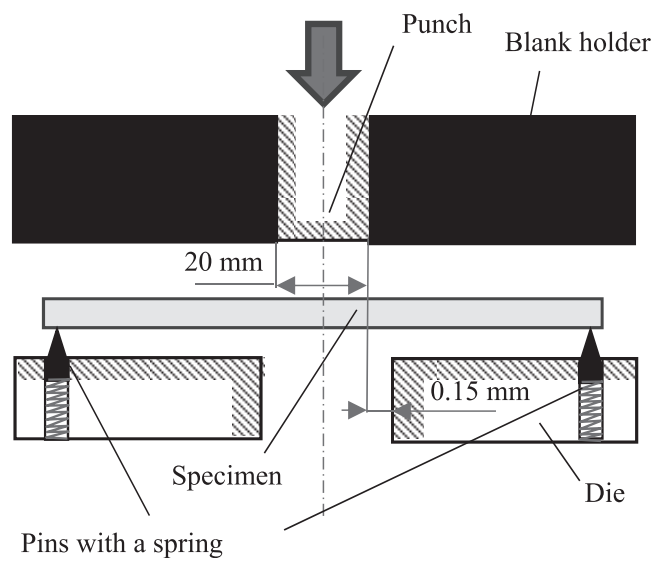

Fig. 3. Schematic image of tools for hot-shearing and quenching.

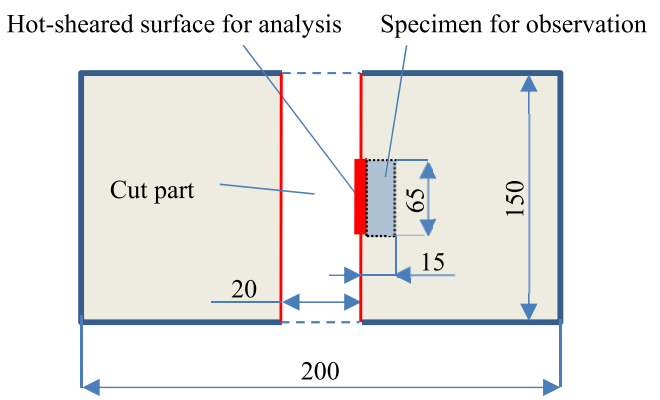

Fig. 4. Specimen for estimation of hydrogen embrittlement cracking. (Online version in color.) 
conditions that the specimen becomes the cathode and the platinum electrode becomes the anode. This process results in an approximately $1.5 \mathrm{ppm}$ hydrogen density in the specimens, which was measured by a gas chromatographic method with a maximum temperature of $400^{\circ} \mathrm{C}$.

\subsubsection{Measurement of Residual Stress}

Residual stress on the hot-sheared surface was measured by X-ray. The stress directions for the measurement are along the cut-edge line and material thickness. The position for this measurement centered on the cut-edge line. For the material thickness, the measurement points were located on the quarter, half, and three fourth of the material thickness. As a reference, cold-sheared surface that hydrogen embrittlement cracking occurred (see Fig. 1) was also measured.

\subsubsection{Micro Structural Analysis}

Microstructure was analyzed by optical observation, hardness measurement, EBSD (electron backscatter diffraction), and TEM (transmission electron microscope) for discussion regarding hydrogen embrittlement cracking.

In the optical observation and hardness measurement, the cross sections of the hot-sheared surface embedded into epoxy were used after polishing and etching by a nital solution. A nano-indentation was applied with $0.01 \mathrm{~N}$ loading forces for the hardness measurement. For the EBSD analyses, specimens were cut off the cross sections of hot-sheared surface and polished by colloidal silica. Thin films for the TEM observations were cut off from the hot-sheared surface using FIB (focused ion beam).

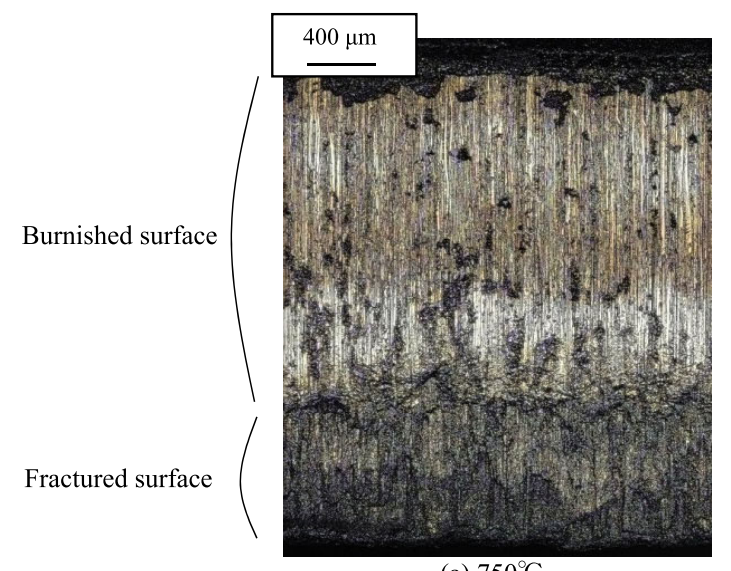

(a) $750^{\circ} \mathrm{C}$

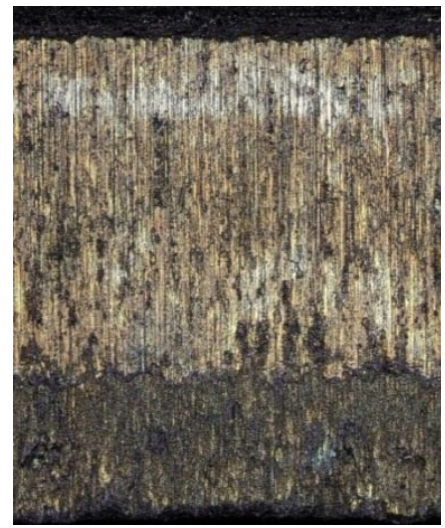

(b) $650^{\circ} \mathrm{C}$

Fig. 5. Hot-sheared surface that contains the $1.5 \mathrm{ppm}$ diffusible hydrogen. (Online version in color.)
For positions of these measurements except for the optical observation, we focused on the fractured surface whose definition is described in Figs. 1 and $\mathbf{5}$ (shown later), due to the fact that hydrogen embrittlement cracking mainly occurs on the fractured surface in the case of cold-shearing. ${ }^{8}{ }^{8}$ Center on the cut-edge line was measured as well as the case in the residual stress measurement.

\section{Results}

\subsection{Appearance of the Hot-sheared Surfaces}

Figure 5 shows appearances of the hot-sheared surfaces. In Fig. 5, no crack was observed on the hot-sheared surfaces at both $650^{\circ} \mathrm{C}$ and $750^{\circ} \mathrm{C}$ shearing temperatures. Cracks were also not observed on other areas not shown in Fig. 5.

Regarding the features of the hot-sheared surface, ratios of the burnished surface by the material thickness are larger than $70 \%$ at the both shearing temperatures from Fig. 5. Difference of the burnished surface ratios among the two shearing temperatures is small. The similar tendencies about burnished surface have been reported by Maki et al. ${ }^{11)}$ and So et al. ${ }^{13)}$

\subsection{Residual Stress}

Residual stress measurement on the hot-sheared surface is shown in Fig. 6 where tension is defined as positive. Figure 6 shows that some residual tensile stresses along the cutedge line and material thickness are over $1.0 \mathrm{GPa}$ at the both

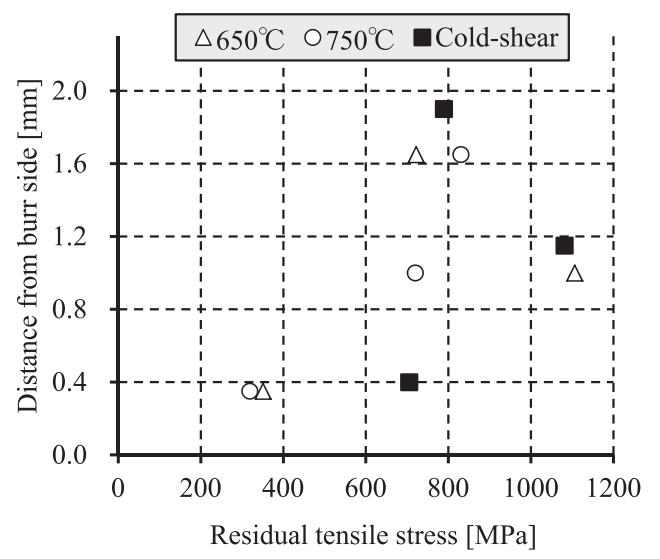

(a) Edge line direction

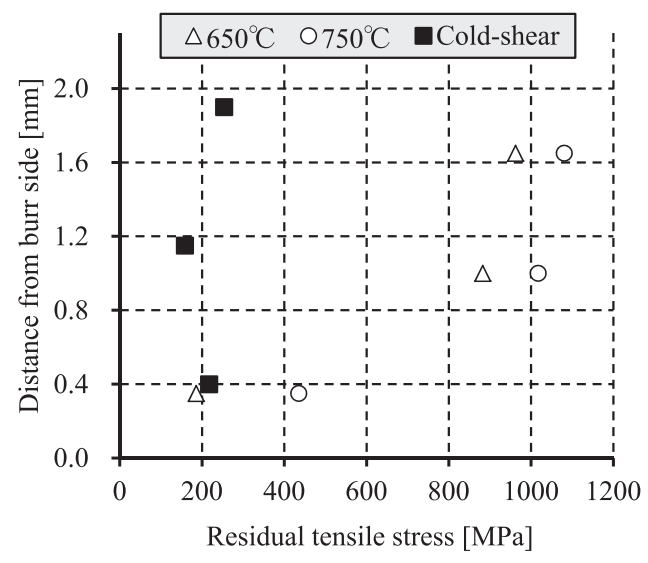

(b) Thickness direction

Fig. 6. Residual tensile stress on sheared surfaces. 
shearing temperatures. It is notable that some values on the hot-sheared surfaces exceed the maximum residual stress on the cold-sheared surface. This tendency is different from the report by Senuma et al. ${ }^{7)}$ that has shown low residual tensile stress on the hot-sheared surfaces. In the detailing of the residual stress distribution, the residual tensile stress distanced $1.0 \mathrm{~mm}$ and $1.65 \mathrm{~mm}$ from the burr side exceed 1.0 $\mathrm{GPa}$ at $750^{\circ} \mathrm{C}$ shearing temperature (see Fig. 6(b)). At $650^{\circ} \mathrm{C}$ shearing temperature, the residual tensile stress distanced $1.0 \mathrm{~mm}$ from the burr side also exceeded 1.0 GPa (see Fig. 6(a)). On the other hand, the residual tensile stresses distanced $0.35 \mathrm{~mm}$ from the burr side are low, regardless of the shearing temperatures. Indeed, the values at these points are lower than $500 \mathrm{MPa}$ along both directions. As for the coldsheared surface, the point distanced $1.15 \mathrm{~mm}$ from the burr side presents over 1.0 GPa of residual tensile stress along the cut-edge line. This value is almost the same as that on the hot-sheared surface at $650^{\circ} \mathrm{C}$ shearing temperature (see Fig. 6(a)). In the material thickness direction, Fig. 6(b) shows that the cold sheared surface presents approximately 200 $\mathrm{MPa}$, which is lower than those on the hot-sheared surfaces.

The above measurements regard that the residual tensile stress is high on the burnished surface and low on the fractured surface in the case of the hot-shearing. Indeed, the upper two points which presented the high residual tensile stresses are located on the burnished surface due to the fact that the ratio of the burnished surface is over $70 \%$, as shown in section 3.1. This distribution is contrary to that on the cold-sheared surface. Generally, residual stress on the fractured surface is higher than that on burnished surface in the case of the cold-shearing. ${ }^{15)}$ Though the detail mechanism is still uncertain, this contrast between hot- and cold-shearing suggests that thermal stress causes the residual high tensile stress on the hot-sheared surface.

\subsection{Microstructure in the Vicinity of the Hot-sheared Surface}

Figure 7 shows optical micrographs in the vicinity of the hot-sheared surface at $750^{\circ} \mathrm{C}$ shearing temperature. The positions of these micrographs are distanced approximately $1.2 \mathrm{~mm}$ (Fig. 7(a)) and $0.4 \mathrm{~mm}$ (Fig. 7(b)) from the burr side. Figure 7 shows clear difference in the microstructure between the region 1, which is located close to the sheared surface, and region 2, which is located distant from sheared surface. Comparison of Figs. 7(a) and 7(b) indicates that the region 1 becomes larger in the vicinity of the fractured surface than the region in the vicinity of the burnished surface.

Figure 8 shows hardness measured at the position close to that shown in Fig. 7(b). Figure 8 indicates that the hardness in region 1 is lower than that in region 2 . Actually, the hardness averages approximately $6.0 \mathrm{GPa}$ in region 2 and approximately $4.0 \mathrm{GPa}$ in region 1 . This measurement is consistent with So et al.'s experiment. ${ }^{13)}$ Although the microstructure has not been identified, So et al. ${ }^{13)}$ also have reported existence of soft phase different from the quenched martensitic microstructure on hot-sheared surfaces.

Subsequently, EBSD analyses of the close position to that shown in Fig. 7(b) are shown in Fig. 9. An inverse pole figure (Fig. 9(a-1)) and image quality map (Fig. 9(a-2)) reveal that laths compose the microstructure in region 2 . Taking into account the hardness shown in Fig. 8, these lath struc-

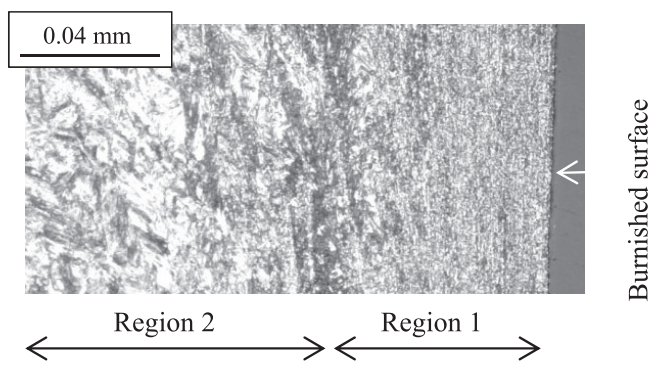

(a) $1.2 \mathrm{~mm}$ from burr side

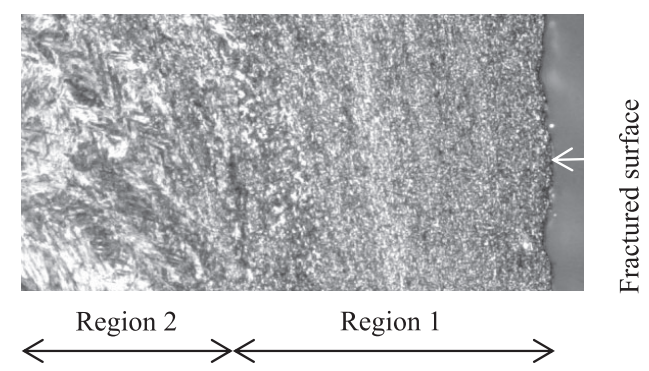

(b) $0.4 \mathrm{~mm}$ from burr side

Fig. 7. Cross section of hot-sheared surface at $750^{\circ} \mathrm{C}$ shearing temperature.

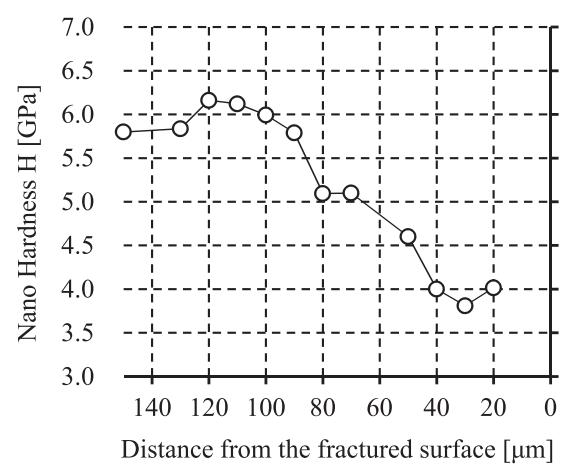

Fig. 8. Hardness in the vicinity of the fractured surface at $750^{\circ} \mathrm{C}$ shearing temperature.

tures are regarded as martensite. Indeed, hardness of martensite contains 0.2 mass $\%$ of carbon density has been measured as approximately $5.5 \mathrm{GPa}$ using nano-indentations. ${ }^{16)}$ On the other hand, sub-micron polygonal grains compose the microstructure in region 1 from Figs. 9(b-1) and 9(b-2). The TEM observations of region 1 confirm the existence of the sub-micron polygonal grains (see Fig. 10). These EBSD analyses and TEM observations indicate that the sub-micron ferrite grains cover the vicinity of the hot-sheared surfaces.

Next, what follows analyzed the hot-sheared surface at $650^{\circ} \mathrm{C}$ shearing temperature. From Fig. 11, which shows optical micrographs in the vicinity of the fractured surface, two different microstructures, regions 1 and 2, arise that are same as the case for $750^{\circ} \mathrm{C}$ shearing temperature. A difference from the case of $750^{\circ} \mathrm{C}$ shearing temperature is the existence of plastic flow lines in region 1. Regarding the hardness, Fig. 12 indicates that the hardness is scattered with respect to the measurement positions and it gradually becomes low with decrease of distance from the fractured surface (see the linearized line in Fig. 12). This hardness measurement implies that mixed soft and hard phases arise in the vicinity of the hot-sheared surface, and the soft phase 


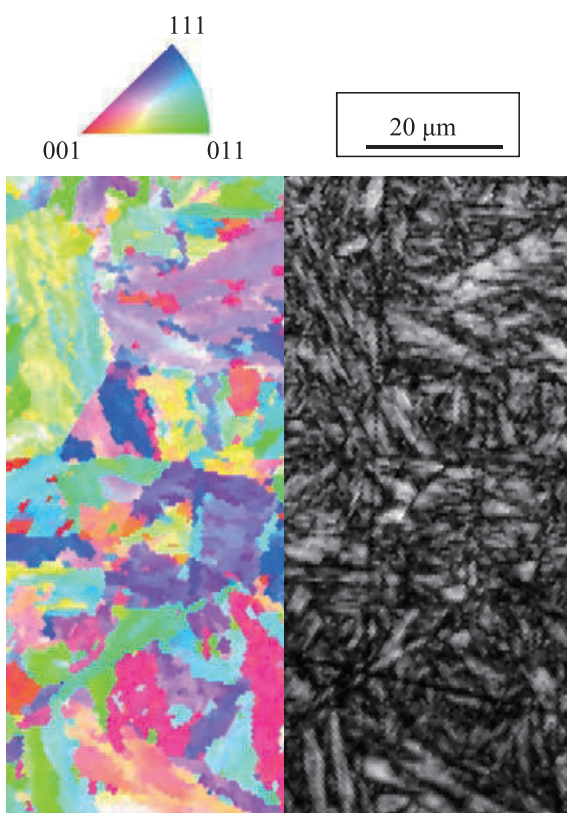

(a-1) IPF

(a-2) IQ

(a) Region 2

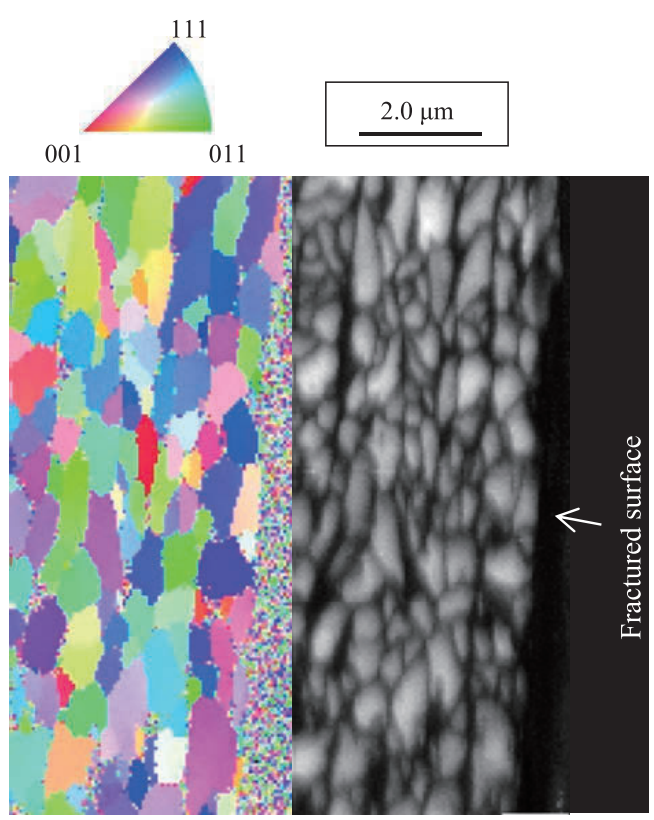

(b-1) IPF

(b-2) IQ

(b) Region 1

Fig. 9. EBSD analysis of the fractured surface at $750^{\circ} \mathrm{C}$ of the shearing temperature.

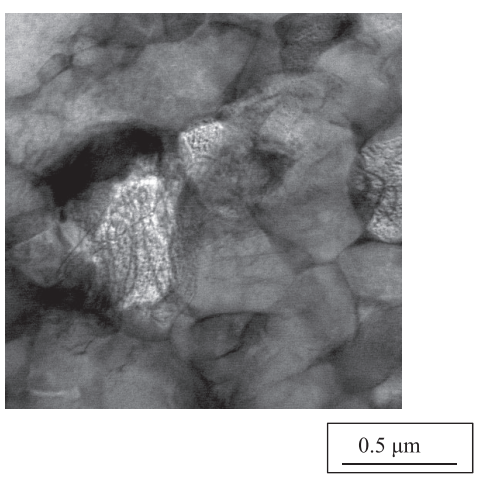

Fig. 10. TEM image on the fractured surface at $750^{\circ} \mathrm{C}$ shearing temperature.

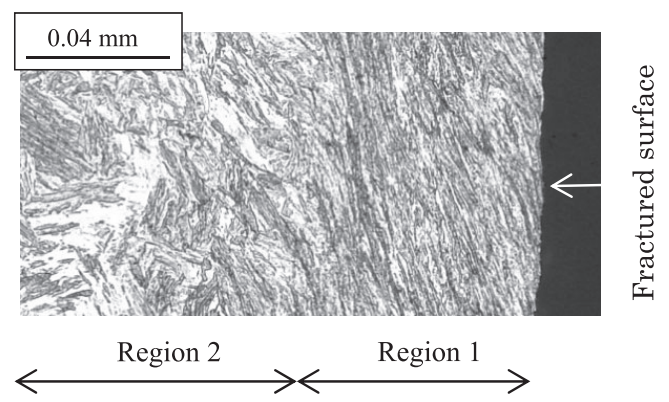

Fig. 11. Cross section of hot-sheared surface at $650^{\circ} \mathrm{C}$ shearing temperature.

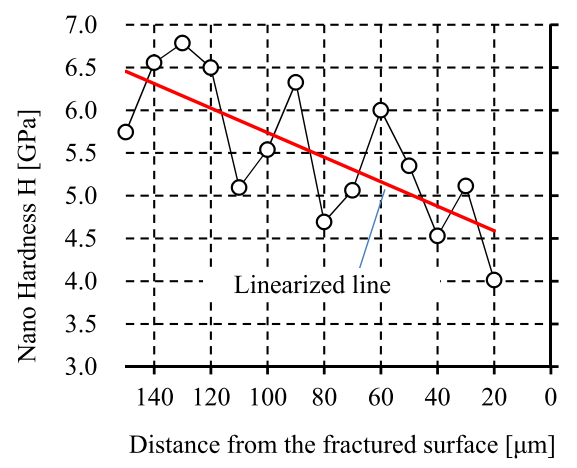

Fig. 12. Hardness in the vicinity of the fractured surface at $650^{\circ} \mathrm{C}$ shearing temperature. (Online version in color.)
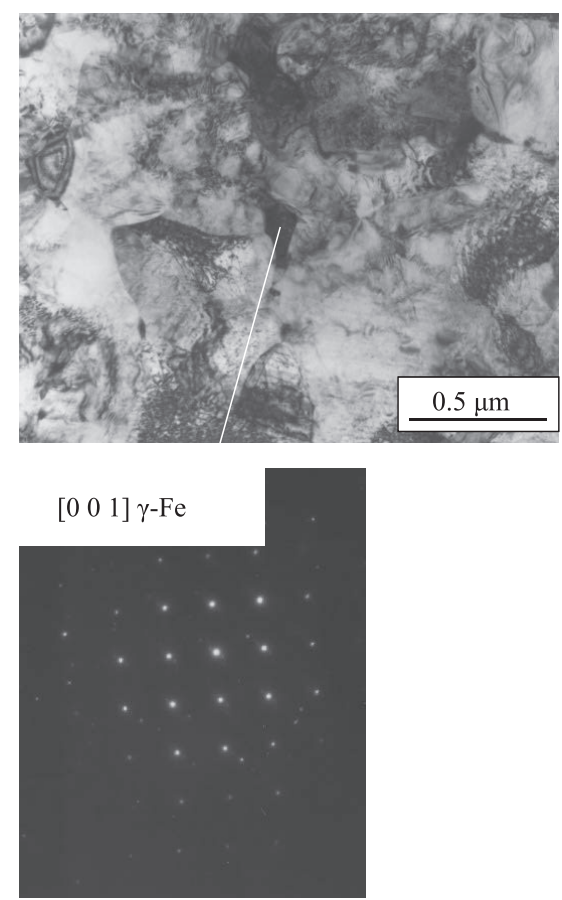

Fig. 13. TEM image of micro structure in the region 1 at $650^{\circ} \mathrm{C}$ shearing temperature.

increases or the hard phase becomes softer with decrease of distance from the hot-sheared surface. As for EBSD analyses, clear images could not be taken (images are not shown here). Considering the plastic flow lines in region 1 (see Fig. 10), the unclear EBSD images were caused by dense dislocations arisen from the plastic deformation. In addition to the above analyses, TEM observations clarified the existence of nanosized retained austenite in the region 1 as shown in Fig. 13. 


\section{Discussion}

Conventionally, possibility of hydrogen embrittlement cracking on a sheared surface have been estimated by residual tensile stress ${ }^{7)}$ and diffusible hydrogen density. ${ }^{8)}$ In detail, Senuma et al. ${ }^{7)}$ has reported that hydrogen embrittlement cracking on a hot-sheared surface occurs when the residual tensile stress exceeds $1.3 \mathrm{GPa}$, and Nishibata et $a l .{ }^{8)}$ has reported that hydrogen embrittlement cracking on coldsheared surface occurs under the condition of over $0.1 \mathrm{ppm}$ of diffusible hydrogen density. The cold-sheared surface observed in this study confirms these reports. Actually, the residual tensile stress on the cold-sheared surface where hydrogen embrittlement cracking occurs is about $1.1 \mathrm{GPa}$ (see Fig. 6(a)).

However, the hydrogen embrittlement cracking on the hot-sheared surface does not follow the criteria reported in the above literatures. ${ }^{7,8)}$ Although the $1.5 \mathrm{ppm}$ diffusible hydrogen density and the over $1.0 \mathrm{GPa}$ residual tensile stress were measured, no hydrogen embrittlement cracking occurs on the hot-sheared surface. This confliction implies additional factors for hydrogen embrittlement cracking on the hot-sheared surface.

The sub-micron microstructure observed in the vicinity of the hot-sheared surface is probably one of these factors. These sub-micron grains increase fracture toughness of the hot-sheared surface to suppress hydrogen embrittlement cracking. Especially, the sub-micron ferrite observed in the case of $750^{\circ} \mathrm{C}$ shearing temperature has high fracture toughness. ${ }^{17)}$ The sub-micron ferrite also affects behaviors of diffusible hydrogen in the vicinity of the hot-sheared surface, which vary depending on microstructure types. ${ }^{18-21)}$

Such sub-micron ferrite is caused by large plastic strain imposed by hot-shearing. It has been reported that the large plastic strain suppresses the transformation from austenite to martensite. Actually, martensitic microstructures, including ferrite and bainite, have been observed in a $22 \mathrm{MnB} 5$ steel that is austenitized, strained, and quenched. ${ }^{22)}$ In this regard, the larger plastic strain or the higher temperature when imposing the plastic strain, the larger the volume fraction of the ferrite. ${ }^{22)}$ Taking into account that shearing process imposes a strain of over 4.0 on the sheared surface, ${ }^{23)}$ the literature $^{22)}$ gives the idea that a large fraction of austenite around the hot-sheared surface transforms to ferrite.

As for the retained austenite in the case of $650^{\circ} \mathrm{C}$ shearing temperature (see Fig. 13), dynamic transformation from austenite to other phases probably causes it. The mechanism of their generation is assumed as follows. During hot-shearing, the austenite grains are dynamically transformed to ferrite with increase of plastic strain. The plastic flow lines in region 1 (see Fig. 11) support this idea. In this dynamic transformation, the large strained austenite assumed to be preferentially transformed. This non-simultaneous transformation causes concentrations of carbon density to nontransformed austenite grains. Such austenite grains become stable after quenching.

Furthermore, it is widely known that ferrite grains that are transformed (or re-crystalized) under large plastic strain are structurally refined, as shown in Fig. 10. ${ }^{24-28)}$ Among these literatures, the mechanism of fine grained ferrite arising on drilled surfaces ${ }^{28)}$ is especially similar to the mechanism dis- cussed in this study. Additionally, rapid cooling rate also contributes to refinement of ferrite grains. ${ }^{29)}$

\section{Summary}

This study investigated the resistance of hydrogen embrittlement cracking on a hot-sheared surface of $22 \mathrm{MnB} 5$ steels. As a result, the following facts were clarified:

(1) Hydrogen embrittlement cracking did not occur on the hot-sheared surfaces.

(2) Diffusible hydrogen density and residual tensile stress on the hot-sheared surface were measured as about $1.5 \mathrm{ppm}$ and over 1.0 GPa, respectively. These values exceed the criteria for hydrogen embrittlement cracking as reported before.

(3) Sub-micron ferrite induced by large plastic deformation composes the microstructure in the vicinity of the hotsheared surface. The existence of this microstructure probably contributes to the high resistance of hydrogen embrittlement cracking on the hot-sheared surface.

\section{REFERENCES}

1) H. Karbasian and A. E. Tekkaya: J. Mater. Process. Technol., 210 (2010), 2103.

2) K. Mori: Press Working, 49 (2011), No. 2, 33

3) H. So, H. Hoffmann and R. Golle: Proc. 2th Int. Conf. on Hot Sheet Metal Forming of High-Performance Steel, CHS, Lulear, (2009), 137.

4) R. Siddiqui, S. Abdul-Wahab and C. Bakheit: Mater. Desingn, 29 (2008), 922

5) J. Ronevich, S. Kim, J. Speer and D. Matlock: Scr. Mater., 66 (2012), 956.

6) G. Lovicu, M. Bottazzi, F. D'aiuto, M. Sanctis, A. Dimatteo, C. Santus and R. Valentini: Metall. Mater. Trans. A, 43A (2012), 4075.

7) T. Senuma, H. Magome, K. Haga, N. Fujioka, Y. Takemoto and K. Shimizu: J. Jpn. Soc. Technol. Plast., 51 (2010), No. 594, 680.

8) T. Nishibata, K. Imai and N. Kojima: CAMP-ISIJ, 25 (2012), 423, CD-ROM

9) K. Mori, S. Saito and S. Maki: CIRP Ann - Manuf. Technol., 57 (2008), 321.

10) K. Mori, T. Maeno and Y. Maruo: CIRP Ann - Manuf. Technol., 61 (2012), 255.

11) S. Maki, T. Hattori and H. Nakanishi: J. Mater. Test. Res. Assoc. Jpn., 54 (2009), No. 1, 29.

12) K. Mori, H. Yamada, T. Maeno and K. Ieda: J. Jpn. Soc. Technol. Plast., 54 (2013), No. 627, 343.

13) H. So, D. Fabmann, H. Hoffmann, R. Gollea and M. Schaper: $J$. Mater. Process. Technol., 212 (2012), 437.

14) C. R. Mackenzie and R. W. Young: JISI, 11 (1971), No. 11, 918

15) T. Matsuno, Y. Kuriyama, H. Murakami, S. Yonezawa and N. Kanamaru: Steel Res. Int., 81 (2010), No. 9, 853.

16) P. Hosemann, J. G. Swadener, D. Kiener, G. S. Was, S. A. Maloy and N. Li: J. Nucl. Mater., 375 (2008), 135.

17) W. B. Morrison and R. L. Miller: Ultrafine Grain Metals, eds. by J. J. Burke and V. Weiss, Syracuse University Press, Syracuse, (1970), 183.

18) W. C. Luu and J. K. Wu: Corros. Sci., 38 (1996), No. 2, 239.

19) G. Han, J. He, S. Fukuyama and K. Yokogawa: Acta Mater., 46 (1998), No. 13, 4559.

20) T. Michler and J. Naumann: Int. J. Hydro. Energy, 35 (2010), No. 2, 821.

21) Y. Mine, K. Tachiban and Z. Horita: Mater. Sci. Eng. A, 528 (2011), No. 28, 8100 .

22) W. Fan, R. B. Park, Y. R. Cho and B. C. De Cooman: Steel Res. Int., 81 (2010), No. 4, 292.

23) T. Matsuno, A. Seto, M. Suehiro, Y. Kuriyama and H. Murakami: Proc. IDDRG 2012, IDDRG2012, Mumbai, (2012), 134.

24) J. G. Li, M. Umemoto, Y. Todaka and K. Tsuchiya: Acta Mater., 55 (2007), No. 4, 1397.

25) A. Azushima and K. Aoki: Mater. Sci. Eng. A, 337 (2002), 45.

26) K. T. Park and D. H. Shin: Mater. Sci. Eng. A, 334 (2002), 79.

$27)$ N. Tsuji, Y. Saito, H. Utsunomiya and S. Tanigawa: Scr. Mater., 40 (1999), No. 7, 795.

28) H. Hidaka, K. Kawasaki, T. Tsuchiyama and S. Takaki: Mater. Trans., 44 (2003), No. 10, 1912.

29) F. Sun, H. Sun, M. Li and B. Sun: Proc. Int. Conf. Phys. Metall. Thermomech. Proc. Steels Other Materials, Vol. 1, ISIJ, Tokyo, (1988), 391. 